\title{
Is clinical intervention in the ultra high risk phase effective?
}

\section{A intervenção clínica na fase de ultra alto risco é eficaz?}

\author{
Philip McGuire, Sudhakar Selvaraj, Oliver Howes \\ Department of Psychosis Studies, Institute of Psychiatry, London SE5 8AF, UK
}

\begin{abstract}
Recent research suggests that early intervention in psychosis might improve the chances of recovery and may even be able to prevent the onset of psychotic disorders. Clinical intervention in subjects at ultra high risk (UHR) of psychosis can have three different objectives. The first aim is to improve the 'prodromal' symptoms and problems that subjects usually present with. The second is to reduce the risk of the subsequent onset of frank psychosis. The third objective is to minimize the delay before the initiation of antipsychotic treatment in the subgroup of UHR subjects that go on to develop a first episode of psychosis. Both pharmacological and psychological interventions appear to be effective in reducing the severity of presenting symptoms in UHR subjects. Clinical trials of the impact of these interventions on the risk of subsequent transition to psychosis have been positive, but have involved small samples, and thus the issue of whether the effects persist in the long term remains to be determined. The monitoring of UHR subjects for the first signs of frank psychosis is an effective means of reducing the delay between the onset of the first episode and the start of antipsychotic treatment. Follow-up studies are required to test whether the reduction in this delay leads to an improved long term outcome. To date, the majority of the interventions that have been used in UHR subjects, such as case management, antipsychotic medication, and cognitive behavior therapy have previously been employed in patients with established psychosis. However, it is possible that treatments that are not normally used in patients with psychotic disorders may prove effective when applied at this stage.
\end{abstract}

Descriptors: Psychotic disorders; Antipsychotic agents; Symptoms; Cognitive Therapy; Treatment outcome

\section{Resumo}

Estudos recentes sugerem que a intervenção precoce na psicose poderia melhorar as chances de recuperação e inclusive evitar o início de transtornos psicóticos. A intervenção clínica para individuos em ultra alto risco (UAR) de psicose pode ter três objetivos diferentes. O primeiro éo de melhorar os sintomas e problemas "prodrômicos" que os individuos normalmente apresentam. O segundo é o de reduzir o risco de psicose franca subsequente. O terceiro objetivo é o de minimizar a demora antes do início do tratamento antipsicótico no subgrupo de individuos em UAR que evoluem para um primeiro episódio psicótico. Tanto as intervençöes farmacológicas como as psicológicas parecem ser eficazes para reduzir a gravidade dos sintomas apresentados pelos individuos em UAR. Ensaios clinicos sobre o impacto dessas intervençôes no risco de transição subsequente para psicose foram positivos, mas envolveram amostras pequenas $e$, dessa forma, a questão de se os efeitos persistem ou não no longo prazo ainda precisa ser resolvida. O monitoramento dos individuos em UAR para os primeiros sinais de psicose franca é uma forma eficaz de reduzir a demora entre o inicio do primeiro episódio e o começo do tratamento antipsicótico. Estudos de acompanhamento são necessários para testar se a redução desse tempo leva a um desfecho melhor no longo prazo. Até hoje, a maioria das intervençöes para indivíduos em UAR, como manejo de caso, medicação antipsicótica e terapia cognitivo-comportamental, foram empregadas anteriormente em pacientes com psicose estabelecida. No entanto, é possivvel que tratamentos que não são normalmente utilizados para pacientes com transtornos psicóticos possam ser eficazes ao serem aplicados nesse estágio.

Descritores: Transtornos psicóticos; Agentes antipsicóticos; Sintomas; Terapia cognitiva; Resultado de tratamento

of this phase has been known for a long time ${ }^{1}$, it is only in the last decade or so that clinicians have tried to clinically intervene at this stage ${ }^{5}$. Conventionally, treatment for psychotic disorders is withheld until the first episode of frank illness.

This recent interest in early clinical intervention has occurred in the context of new research on the neurobiology of the UHR phase. Magnetic resonance imaging (MRI) studies have shown
Correspondence

Philip McGuire

Box P067

De Crespigny Park

SE5 8AF

E-mail: philip.mcguire@kcl.ac.uk 
that reductions in grey matter volume in the frontal and temporal cortices, the limbic system and cerebellum are evident in UHR subjects, well before the first episode of psychosis, ${ }^{6,7,8}$. Similarly, both dopaminergic and glutamatergic function, as measured using F-DOPA PET and MR spectroscopy, respectively, are altered before the first episode of psychosis ${ }^{9,10,11}$, and functional MRI studies have shown that UHR subjects display abnormalities that are qualitatively similar to those seen in patients with schizophrenia ${ }^{12,13,14}$. Furthermore, longitudinal neuroimaging studies in UHR subjects indicate that some of these structural and neurochemical abnormalities progress as subjects make the transition from the prodromal to the psychotic state ${ }^{6,15,16}$. Such progressive changes suggest that there is an active neuropathological process underlying the onset of illness at this stage, which might therefore be arrested through clinical intervention.

The aim of this article is to provide a state-of-the-art review of studies that have sought to examine the effectiveness of clinical intervention in UHR subjects.

\section{Subjects at ultra high risk of psychosis}

People who are at UHR of psychosis are usually identified on the basis of a combination of trait and state risk factors. The PACE criteria $^{17}$ require that subjects have one or more of the following: (1) attenuated psychotic symptoms, (2) brief limited intermittent psychotic symptoms within the last year, and (3) a significant decrease in functioning, maintained for at least a month, plus either a schizotypal personality disorder or a first-degree relative with a psychotic disorder. The criteria of the Structured Interview for Prodromal Syndromes (SIPS ${ }^{18}$ ), developed in North America, are similar to the PACE criteria. UHR subjects can also be identified on the basis of subjective changes in thinking, language and attention, termed 'basic symptoms' ${ }^{19}$. Subjects meeting either of these criteria have a risk of transition to psychosis of $15-54 \%$ in the next 24 months $^{4,20}$. Many centers now use both sets of inclusion criteria, as they are based on complementary types of clinical features. A recent meta-analysis of 27 follow-up studies estimated the mean risk of transition to psychosis to be $31 \%$ in 24 months $^{14}$, and found that the risk was similar for studies using either set of inclusion criteria.

\section{Treatment of presenting symptoms}

The first aim of clinical intervention in UHR subjects is to relieve their presenting problems and symptoms. These are often the patient's main concern, as they are usually what led to their referral. UHR subjects typically present with distressing symptoms (attenuated psychotic symptoms, anxiety, and depression) that occur in the context of social and vocational problems ${ }^{21}$. The presenting subject will often want some form of treatment or assistance for these problems, and they are thus described as 'helpseeking' individuals (as distinct from subjects who may experience psychotic symptoms but do not seek clinical help).

Woods et al. ${ }^{22}$ studied the acute symptomatic effects of olanzapine versus placebo in UHR subjects $(n=31$ and $n=29$ in each arm) in a double-blind randomized controlled trial. They found that at an average dose of $10.2 \mathrm{mg} /$ day, olanzapine had significantly improved symptom levels at eight weeks, but was also associated with significant weight gain. In an open-label trial, Ruhrmann et al., randomly assigned UHR subjects to a needs-focused intervention, with $(n=65)$ or without $(n=59)$ amisulpride ${ }^{23}$. They found that amisulpride significantly reduced attenuated and full-blown psychotic symptoms, basic, depressive and negative symptoms, and improved global functioning at 12 weeks. Similarly, Woods et al. ${ }^{24}$, in another open-label study, found that aripiprazole reduced positive and negative symptoms scores at eight weeks, although this was associated with mild akathisia.

A trial of cognitive behavioral therapy (CBT) in UHR subjects reported that this improved attenuated positive symptoms, with some benefits sustained at three years of follow-up ${ }^{25}$. Bechdolf et al. recruited young people $(n=113)$ meeting criteria for the early initial prodromal states and provided both individual and group CBT, comparing this to supportive counseling ${ }^{26}$. The CBT targeted selfexperienced cognitive thought and perception deficits, negative symptoms, anxiety, depressive symptoms, family and occupational problems. CBT was not superior to supportive counseling, with both treatments leading to significant improvements in social adjustment measures. Addington et al. compared CBT and supportive therapy ${ }^{27}$. They reported no group differences, but both therapy groups made significant improvements in attenuated positive symptoms, anxiety and depression relative to baseline.

\section{Reducing the risk of psychosis}

A longer-term objective of treatment is to reduce the risk that the UHR subject will go on to develop a full-blown psychotic disorder. If an UHR subject is going to develop psychosis, in most (but not all) cases this will occur within two years of presentation ${ }^{3,4,14}$. Over the last 10 years, a number of clinical trials have examined the impact of intervention on the risk of transition to psychosis in this group.

\section{Pharmacological trials Antipsychotic medication}

To date, two randomized clinical trials using antipsychotic medication have been conducted. In the first study, UHR subjects received a needs-based intervention plus either risperidone (1-2 $\mathrm{mg}$ /day) and CBT, or needs-based intervention alone for six months. After 6 months, 3 of 31 subjects in the actively treated group had developed a psychotic disorder, compared to 10 of 28 in the control $\mathrm{arm}^{28}$. A further 3 subjects in the active treatment group had become psychotic at 12 months of follow-up. However, the study groups were not blinded to the treatment, and the effects of treatment did not persist at either 12 months or 3 years of follow-up ${ }^{28}$. Because the active treatment arm involved both risperidone and $\mathrm{CBT}$, it is unclear if the beneficial effect was due to the pharmacological or the psychological treatment, or both. McGlashan et al. compared the effects of olanzapine $(\mathrm{n}=31)$ vs placebo $(n=29)$ for 12 months in a double-blind randomized 
trial $^{29}$. There was a high dropout rate, with only 33 subjects completing the trial, and only 17 completing the 12 -month follow-up period. There was a strong trend for a reduced rate of conversion to psychosis at 12 months with olanzapine. However, the olanzapine group gained a mean $8 \mathrm{~kg}$ over a period of 12 months, and were more likely to have dropped out than the placebo group ${ }^{29}$.

\section{Antidepressants}

Up to $50 \%$ of UHR subjects present with low mood and anxiety, in addition to attenuated psychotic symptoms ${ }^{30}$. Antidepressants are commonly used to treat these symptoms in UHR subjects, and until recently there was no expectation that this would influence the risk of transition to psychosis. However, in a naturalistic study $(n=48)$, Cornblatt et al. followed up young adolescents with atrisk symptoms who had been prescribed either an antidepressant $(\mathrm{n}=20)$ or an atypical antipsychotic $(\mathrm{n}=28)$ by their treating clinician $^{31}$. They observed that while both groups improved symptomatically, there had been no transitions to psychosis in the group who had been prescribed antidepressants. However, 11 of the 12 UHR subjects in the antipsychotic group who had converted to psychosis were non-compliant with antipsychotic medication. It is also possible that the treating clinicians chose to prescribe antidepressants to the UHR subjects in whom they were less concerned about the risk of later psychosis, and used antipsychotics in those that they thought were most at risk. Nevertheless, Fusar-Poli and colleagues found similar results in a retrospective naturalistic study of an independent UHR sample, with a much lower transition rate in the subjects who had been treated with antidepressants than in tho se who had been given either antipsychotics or $\mathrm{CBT}^{32}$.

Although unexpected, these findings are consistent with cognitive models of psychosis ${ }^{33}$ that propose that isolated psychotic experiences are more likely to develop into frank psychosis if they occur in the context of depression. Moreover, it is possible that the putative effect of CBT on the risk of transition (below) reflects an impact on depressive, as opposed to psychotic, symptoms. In addition, subjects in the community who report psychotic experiences in the presence of depressed mood have a higher risk of developing a psychotic disorder than those who do not ${ }^{34}$. Treatment with antidepressants may influence the response to environmental stress and therefore alter the risk of psychosis ${ }^{35}$. However, because these findings are based on retrospective naturalistic studies, they require replication in a randomized trial.

\section{CBT}

CBT is widely used in UHR subjects. For example, in the OASIS service, when offered the choice of treatment, $70 \%$ of UHR subjects were willing to have CBT, but only $25 \%$ accepted antipsychotic medication ${ }^{36}$. This willingness to try CBT may reflect the fact that many UHR subjects are open to the possibility that their symptoms may be related to an underlying disorder ${ }^{37}$. Data from two randomized clinical trials of CBT in UHR subjects have been published to date $e^{25,27,38}$. Morrison et al. reported that CBT was superior to clinical monitoring in reducing the progression to psychosis over 12 months (2/35 developed psychosis in the CBT arm, vs 5/23 in the monitoring arm) ${ }^{38}$. However, this effect was no longer significant at three years of follow-up ${ }^{25}$. Addington et al. compared CBT with supportive therapy ${ }^{27}$. Although more subjects in the supportive therapy group developed psychosis than in the CBT group, the difference was not statistically significant ${ }^{27}$.

\section{Eicosapentaenoic acid (EPA)}

Amminger et al. conducted a 12-week trial comparing eicosapentaenoic acid (EPA) with placebo in UHR subjects ${ }^{39}$. At 12 months of follow-up, 2 of 41 individuals in the EPA group had developed psychosis, compared to 11 of 40 in the placebo group. There were also improvements in the levels of attenuated positive and negative symptoms in the active EPA treatment group. These findings are of particular interest, as EPA is an example of what early intervention clinicians would regard as an ideal intervention for UHR subjects 5 . It is an inexpensive nutritional supplement, with minimal side effects, and which may have beneficial effects on physical health, which is particularly poor in patients with psychosis. Moreover, in contrast to antipsychotic medication, treatment with EPA is non-stigmatizing. However, the promising initial results require replication in a larger sample, and a large multi-center study of EPA in UHR subjects is currently ongoing 5 .

Because only a minority (about 30\%) of UHR subjects will subsequently become frankly psychotic ${ }^{14}$, there are concerns about the ethics of clinical intervention to reduce the risk of psychosis in this group ${ }^{5,40}$. Thus, the potential benefit of reducing the risk of psychosis has to be balanced against the risk that subjects who might never have developed psychosis will receive treatments that may be associated with adverse effects and stigmatization. However, these concerns relate specifically to treatment that is designed to prevent the onset of psychosis: they are less relevant to the treatment of the presenting symptoms, which occur in all UHR subjects and which the subjects usually want to have treated.

\section{Reducing the duration of untreated psychosis (DUP)}

A potential benefit of intervention at the UHR stage that is often overlooked stems from the engagement of subjects with mental health services before the first episode of psychotic illness. If a clinician is already seeing the patient, has established a clinical rapport with him/her, and the patient is already aware of the early signs of psychotic illness and what happens should psychosis develop, it should be easier to detect the first onset of psychosis and reduce the delay before the initiation of its treatment. In addition, the patient is more likely to understand the rationale for treatment and to accept that it is worthwhile. As a short DUP is associated with a better prognosis (above), reducing the DUP through engagement in the UHR phase may therefore improve the subsequent clinical outcome. To date, only one study has examined this issue. In subjects engaged by the OASIS service in London, and who subsequently developed psychosis, the average DUP was 
10 days. This compared with a DUP of 12 months in patients from the same geographical area who did not present until they were experiencing their first episode of psychosis ${ }^{36}$. The patients who developed psychosis after engagement in the UHR phase were also less likely to require admission, compulsory treatment or police involvement. This probably reflects the initiation of treatment at the start of the first episode (as opposed to several months later), when the illness is less severe, and patients are more willing to cooperate with the clinical team. Further work is required to assess whether this approach has beneficial effects on long-term clinical and functional outcome.

\section{Limitations of trials to date}

The results of the above studies suggest that both pharmacological and psychological intervention at the UHR stage can reduce the severity of the presenting symptoms. However, whether intervention can delay or prevent the onset of a psychotic disorder remains unclear, mainly because most trials in this area to date have been underpowered, due to small sample sizes. A further caveat is that, in the trials conducted so far, both the duration of the interventions and the follow-up periods have been relatively short. It thus remains unclear how long treatment in the UHR stage should be given for. Given that the majority of transitions to psychosis occur within the first two years after presentation, a reasonable approach would be to provide treatment for this period, thereby covering the 'window of highest risk'. However, in practice, some UHR subjects are unwilling to continue with active treatment for this length of time, particularly if their presenting symptoms have resolved.

\section{Outstanding issues}

\section{Duration of specialized intervention}

It remains unclear how long specialized treatment should be delivered for. At present, a popular approach is to provide care for two years, as this period is when the risk of transition to psychosis is maximal.

\section{Multisite clinical trials}

A key limitation of all trials to date in UHR subjects has been limited sample size, and a resultant lack of power to test the effectiveness of interventions. It is unlikely that any single site can recruit sufficiently large numbers of this population for a definitive clinical trial, as UHR subjects are relatively difficult to identify and engage. This problem can be overcome by conducting multi-center trials, and these are now ongoing ${ }^{5,41,42}$.

\section{Clinical staging}

Clinical staging has been proposed as a model for a future intervention strategy in UHR subjects 5 . This suggests that the nature of the intervention should depend on the stage of illness, progressing in a step-wise fashion from benign, low-risk treatments towards more intensive interventions for those who do not show a response, and who may be more at risk. McGorry et al. suggest that through clinical staging, it is possible to provide acceptable and less stigmatizing interventions to patients ${ }^{5}$.

\section{Targeted intervention}

Because only a minority of UHR subjects will later develop psychosis, there is great interest in determining factors that could identify the subgroup of subjects that are destined to become psychotic, so that preventative treatment could be given to those who need it most. This would permit a more efficient use of clinical resources and would be more acceptable from an ethical perspective. A number of clinical measures have been identified that are associated with the later onset of psychosis within UHR samples. The multi-center NAPLS study reported that the combination of a family history of schizophrenia, recent functional deterioration, unusual thought content and suspiciousness/paranoia, and social functioning deficits provided a positive predictive power for later psychosis of up to $80 \%{ }^{4}$. The EPOS multi-center study found that SIPS positive score, bizarre thinking, sleep disturbances, schizotypal personality disorder, global functioning score in the past year, and years of education were the best predictor variables ${ }^{43}$. Neuropsychological studies of UHR subjects at clinical presentation have suggested that certain deficits, particularly impairments in episodic memory, are more marked in subjects who later develop psychosis ${ }^{44,45,46}$.

Neuroimaging studies of UHR subjects at presentation have found that the subsequent onset of psychosis is associated with smaller prefrontal and medial temporal volumes ${ }^{6,7,8}$, increased prefrontal, medial temporal, lateral temporal and midbrain activation ${ }^{47,48}$, increased subcortical dopamine function ${ }^{10}$, and an alteration in the relationship between subcortical dopamine function and medial temporal glutamate levels ${ }^{49}$. Longitudinal neuroimaging studies have also linked transition to psychosis with progressive changes in some of these measures subsequent to presentation ${ }^{6,15,16,50}$.

While there have thus been a number of clinical, neuropsychological and neuroimaging findings linked to the onset of psychosis in UHR subjects, these have generally been identified at a group level. However, in clinical practice, the psychiatrist needs to be able to use such measures from an individual patient to make a reliable prediction about the likelihood of later transition in that person. One method which has the potential to permit predictions at an individual subject level is machine learning ${ }^{51}$, which allows a comparison of a given patient's data with existing datasets that are representative of subjects who have or have not subsequently developed psychosis ${ }^{52}$. To date, this approach has been applied to neuroimaging data form UHR subjects, but it can be applied to any form of data, and can incorporate clinical, cognitive, and neuroimaging data in the same analysis.

\section{Conclusions}

Both pharmacological and psychological treatments in UHR subjects appear to improve presenting symptoms. Trials of their ability to reduce the risk of later psychosis have been positive, but have involved small samples. It is also unclear if the reported beneficial effects persist in the long term, and 
it remains to be established how long intervention in UHR subjects should be given for. The clinical monitoring of UHR subjects for early signs of frank psychosis is a very effective means of reducing the DUP, and appears to reduce the severity of the first episode. Follow-up studies are required to test whether this reduction in DUP leads to improved clinical outcomes.

\section{Disclosures}

\begin{tabular}{|c|c|c|c|c|c|c|c|}
\hline $\begin{array}{l}\text { Writing group } \\
\text { member }\end{array}$ & Employment & $\begin{array}{l}\text { Research } \\
\text { grant }^{1}\end{array}$ & $\begin{array}{l}\text { Other research } \\
\text { grant or medical } \\
\text { continuous } \\
\text { education }^{2}\end{array}$ & $\begin{array}{l}\text { Speaker's } \\
\text { honoraria }\end{array}$ & $\begin{array}{c}\text { Ownership } \\
\text { interest }\end{array}$ & $\begin{array}{c}\text { Consultant/ } \\
\text { Advisory board }\end{array}$ & Other $^{3}$ \\
\hline \multicolumn{8}{|l|}{$\begin{array}{l}\text { Sudhakar } \\
\text { Selvaraj }\end{array}$} \\
\hline
\end{tabular}

\section{References}

1. Hafner H. Onset and early course as determinants of the further course of schizophrenia. Acta Psychiatr Scand Suppl. 2000;(407):44-48.

2. Fusar-Poli P, Bonoldi I, Yung AR, Borgwardt S, Kempton MJ, Barale F, Caverzasi E, McGuire P. Predicting psychosis: a meta-analysis of evidence . Arch Gen Psychiatry. In Press 2011.

3. Yung AR, Phillips LJ, Yuen HP, McGorry PD. Risk factors for psychosis in an ultra high-risk group: psychopathology and clinical features. Schizophr Res. 2004;67(2-3):131-142.

4. Cannon TD, CadenheadK, Cornblatt B, Woods SW, Addington J, Walker E, Seidman LJ, Perkins D, TsuangM, McGlashan T, Heinssen R,. Prediction of psychosis in youth at high clinical risk: a multisite longitudinal study in North America. Arch Gen Psychiatry. 2008;65(1):28-37.

5. McGorry PD, Nelson B, Amminger GP., Bechdolf A, Francey SM, Berger G, Riecher-Rössler A, Klosterkötter J, Ruhrmann S, Schultze-LutterF, Nordentoft M, Hickie I, McGuire P, Berk M, Chen EY, Keshavan MS, Yung AR. Intervention in individuals at ultra-high risk for psychosis: a review and future directions. J Clin Psychiatry. 2009;70(9):1206-1212.

6. Pantelis C, Velakoulis D, McGorry PD, Wood SJ, Suckling J, Phillips LJ, Yung AR, Bullmore ET, Brewer W, Soulsby B, Desmond P, McGuire PK. Neuroanatomical abnormalities before and after onset of psychosis: a crosssectional and longitudinal MRI comparison. Lancet. 2003;361(9354):281288.

7. Borgwardt SJ, Riecher-Rossler A, Dazzan P, Chitnis X, AstonJ, Drewe M, Gschwandtner U, Haller S, PflugerM, Rechsteiner E, D'Souza M, Stieglitz RD, Radu EW, McGuire PK. Regional gray matter volume abnormalities in the at risk mental state. Biol Psychiatry. 2007;61(1):1148-1156.

8. Mechelli A, Riecher-Rössler A, MeisenzahlEM, TogninS, WoodSJ, Borgwardt SJ, Koutsouleris N, Yung AR, Stone JM, Phillips LJ, McGorry PD, Valli I, Velakoulis D, Woolley J, Pantelis C, McGuire P. Neuroanatomical abnormalities that predate the onset of psychosis: A multicenter study. Arch Gen Psychiatry.2011;68(5): 489-495.

9. Howes OD, Montgomery AJ, Asselin MC, MurrayRM, ValliI, TabrahamP, Bramon-Bosch E, ValmaggiaLJohns L, Broome M, McGuire PK, Grasby
PM. Elevated striatal dopamine function linked to prodromal signs of schizophrenia. Arch Gen Psychiatry. 2009; 66(1):13-20.

10. Howes O, Bose S, Turkheimer F, Valli I, Egerton A, Valmaggia L, Murray $\mathrm{R}, \mathrm{McGuire}$ P. Dopamine synthesis capacity prior to the subsequent onset of psychosis: an [18F]-DOPA PET imaging study. Am J Psychiatry. In Press 2011. 11. Stone JM, Day F, Tsagaraki H, Valli I, McLean MA, Lythgoe DJ, O'Gorman RL, Barker GJ, McGuire PK; OASIS. Glutamate dysfunction in people with prodromal symptoms of psychosis: relationship to gray matter volume. Biol Psychiatry. 2009;66(6):533-39.

12. Broome MR, Matthiasson P, Fusar-Poli P, Woolley JB, Johns LC, Tabraham P, Bramon E, Valmaggia L, Williams SC, Brammer MJ, Chitnis X, McGuire PK. Neural correlates of executive function and working memory in the 'atrisk mental state'. Br J Psychiatry. 2009;194(1): 25-33.

13. Fusar-Poli P, Howes OD, Allen P, Broome M, Valli I, Asselin MC, Grasby PM, McGuire PK. Abnormal frontostriatal interactions in people with prodromal signs of psychosis: a multimodal imaging study. Arch Gen Psychiatry. 2010;67(7):683-691.

14. Fusar-Poli P, Howes OD, Allen P, Broome M, Valli I, Asselin MC, Montgomery AJ, Grasby PM, McGuire P. Abnormal prefrontal activation directly related to pre-synaptic striatal dopamine dysfunction in people at clinical high risk for psychosis. Mol Psychiatry. 2011;16(1):67-75.

15. Howes O, Bose S, Turkheimer F, Valli I, Egerton A, StahlD, Valmaggia L, Allen P, Murray R, McGuire P. Progressive increase in striatal dopamine synthesis capacity as patients develop psychosis: A PET study. Mol Psychiatry. 2011;16(9):885-6.

16. Egerton A, Stone J, Chaddock C, Howard R, Barker G, McLean M, Lythgoe D, O'Gorman R, McGuire P. Progressive decline in thalamic glutamate levels prior to the onset of psychosis. Submitted 2011.

17. Yung AR, Phillips LJ, McGorry PD, McFarlane CA, Francey S, Harrigan S, Patton GC, Jackson HJ.. Prediction of psychosis. A step towards indicated prevention of schizophrenia. Br J Psychiatry Suppl. 1998;172(33):14-20.

18. McGlashan TH, Miller TJ, Woods SW, Rosen JL, Hoffman RE, Davidson L. Structured clinical interview for prodromal syndromes. Yale School of Medicine: PRIME Research Clinic; 2001. 
19. Klosterkotter J, Hellmich M, Steinmeyer EM, Schultze-Lutter F 2001. Diagnosing schizophrenia in the initial prodromal phase. Arch Gen Psychiatry. 2001;58(2):158-164.

20. Yung AR, Yuen HP, Berger G, Francey S, Hung TC, Nelson B, Phillips L, McGorry P. Declining transition rate in ultra high risk (prodromal) services: dilution or reduction of risk? Schizophr Bull. 2007;33(3):673-681.

21. Broome MR, Woolley JB, Johns LC, Valmaggia LR, Tabraham P, Gafoor $\mathrm{R}$, Bramon E, McGuire PK Outreach and support in south London (OASIS): implementation of a clinical service for prodromal psychosis and the at risk mental state. Eur Psychiatry. 2005;20(5-6):372-378.

22. Woods SW, Breier A, Zipursky RB, Perkins DO, Addington J, Miller TJ, Hawkins KA, Marquez E, Lindborg SR, Tohen M, McGlashan TH. Randomized trial of olanzapine versus placebo in the symptomatic acute treatment of the schizophrenic prodrome. Biol Psychiatry. 2003;54(4):453464.

23. Ruhrmann S, Bechdolf A, Kuhn KU, Wagner M, Schultze-Lutter F, Janssen B, Maurer K, Hafner H, Gaebel W, Moller HJ, Maier W, Klosterkotter J, 2007. Acute effects of treatment for prodromal symptoms for people putatively in a late initial prodromal state of psychosis. Br J Psychiatry Suppl.. 2007; 51:s88-95.

24. Woods SW, Tully EM, Walsh BC, Hawkins, KA, Callahan JL, Cohen SJ, Mathalon DH, Miller TJ, McGlashan TH. Aripiprazole in the treatment of the psychosis prodrome: an open-label pilot study. BrJ Psychiatry Suppl. 2007;51: s96-101.

25. Morrison AP, French P, Parker S, Roberts M, Stevens H, Bentall RP, Lewis $S$ W.. Three-year follow-up of a randomized controlled trial of cognitive therapy for the prevention of psychosis in people at ultrahigh risk. Schizophr Bull. 2007;33(3):682-687.

26. Bechdolf A, Wagner M, Veith V, Ruhrmann S, Pukrop R, BrockhausDumke A, Berning J, Stamm E, Janssen B, Decker P, Bottlender R, Moller HJ, Gaebel W, Maier W, Klosterkotter J.. Randomized controlled multicentre trial of cognitive behaviour therapy in the early initial prodromal state: effects on social adjustment post treatment. Early Interv Psychiatry. 2007;1(1):71-78.

27. Addington J, Epstein, Liu L, French P, Boydell KM, Zipursky RB, A randomized controlled trial of cognitive behavioral therapy for individuals at clinical high risk of psychosis. Schizophr Res. 2011;125(1):54-61.

28. McGorry PD, Yung AR, Phillips LJ, Yuen HP, Francey S, Cosgrave EM, Germano D, Bravin J, McDonald T, Blair A, Adlard S, Jackson H. Randomized controlled trial of interventions designed to reduce the risk of progression to first-episode psychosis in a clinical sample with subthreshold symptoms. Arch Gen Psychiatry. 2002;59(10):921-928.

29. McGlashan TH, Zipursky RB, Perkins D, Addington J, Miller T, Woods SW, Hawkins KA, Hoffman RE, Preda A, Epstein I, Addington D, Lindborg S, Trzaskoma Q, Tohen M, Breier A. Randomized, double-blind trial of olanzapine versus placebo in patients prodromally symptomatic for psychosis. Am J Psychiatry. 2006;163(5):790-799.

30. Yung AR, Yuen HP, McGorry PD, Phillips LJ, Kelly D, Dell'Olio M, Francey SM, Cosgrave EM, Killackey E, Stanford C, Godfrey K, Buckby J. Mapping the onset of psychosis: the Comprehensive Assessment of At-Risk Mental States. Aust N Z J Psychiatry. 2005;39(11-12):964-971.

31. Cornblatt BA, Lencz T, Smith CW, Olsen R, Auther AM, Nakayama E, Lesser ML, Tai JY, Shah MR, Foley CA, Kane JM, Correll CU. Can antidepressants be used to treat the schizophrenia prodrome? Results of a prospective, naturalistic treatment study of adolescents. J Clin Psychiatry. 2007;68(4):546-557.

32. Fusar-Poli P, Valmaggia L, McGuire P. Can antidepressants prevent psychosis? Lancet. 2007;370(9601):1746-1748.

33. Garety PA, Kuipers E, Fowler D, Freeman D, Bebbington PE. A cognitive model of the positive symptoms of psychosis. Psychol Med. 2001;31(2):189195

34. Krabbendam L, Myin-Germeys I, Hanssen M, de Graaf R, Vollebergh W, Bak M, van Os J. Development of depressed mood predicts onset of psychotic disorder in individuals who report hallucinatory experiences. $\mathrm{Br}$ Psychol. 2005;44(Pt1):113-125.

35. Berton O, McClung CA, Dileone RJ, Krishnan V, Renthal W, Russo SJ, Graham D, Tsankova NM, Bolanos CA, Rios M, Monteggia LM, Self DW, Nestler EJ. Essential role of BDNF in the mesolimbic dopamine pathway in social defeat stress. Science. 2006;311(5762):864-868.

36. Valmaggia LR, McCrone P, Knapp M, Woolley JB, Broome MR, Tabraham P, Johns LC, Prescott, C, Bramon E, Lappin J, Power P, McGuire PK Economic impact of early intervention in people at high risk of psychosis. Psychol Med. 2009; 39(10): 1617-1626.

37. Lappin JM, Morgan KD, Valmaggia LR, Broome MR, Woolley JB, Johns LC, Tabraham P, Bramon E, McGuire PK. Insight in individuals with an At Risk Mental State. Schizophr Res. 2007;90(1-3):238-244.

38. Morrison AP, French P, Walford, L, Lewis SW, Kilcommons A, Green J, Parker S, Bentall RP. Cognitive therapy for the prevention of psychosis in people at ultra-high risk: randomized controlled trial. Br J Psychiatry. 2004;185:291-297.

39. Amminger GP, Schäfer MR, Papageorgiou K, Klier CM, Cotton SM, Harrigan SM, Mackinnon A, McGorry PD, Berger GE. Long-chain omega-3 fatty acids for indicated prevention of psychotic disorders: a randomized, placebo-controlled trial. Arch General Psychiatry. 2010;67(2):146-154.

40. McGuire P. Prodromal intervention: the need for evaluation. J Ment Health. 2002;11:469-470.

41. Morrison AP, Stewart SL, French P, Bentall RP, Birchwood M, Byrne R, Davies LM, Fowler D, Gumley AI, Jones PB, Lewis SW, Murray GK, Patterson P, Dunn G. Early detection and intervention evaluation for people at high-risk of psychosis-2 (EDIE-2): trial rationale, design and baseline characteristics. Early Interv Psychiatry. 2011;5(1):24-32.

42. Rietdijk J, Dragt S, Klaassen R, Ising H, Nieman D, Wunderink L, Delespaul P, Cuijpers P, Linszen D, van der Gaag M. A single blind randomized controlled trial of cognitive behavioural therapy in a help-seeking population with an At Risk Mental State for psychosis: the Dutch Early Detection and Intervention Evaluation (EDIE-NL) trial. Trials. 2010;11:30.

43. Ruhrmann S, Schultze-Lutter F, Salokangas RK, Heinimaa M, Linszen D, Dingemans P, Birchwood M, Patterson P, Juckel G, Heinz A, Morrison A, Lewis S, von Reventlow HG, Klosterkotter J. Prediction of psychosis in adolescents and young adults at high risk: results from the prospective European prediction of psychosis study. Arch Gen Psychiatry. 2010;67(3): 241-251.

44. Brewer WJ, Wood SJ, Phillips LJ, Francey SM, Pantelis C, Yung AR, Cornblatt B, McGorry PD. Generalized and specific cognitive performance in clinical high-risk cohorts: a review highlighting potential vulnerability markers for psychosis. Schizophr Bull. 2006; 32(3):538-555.

45. Pukrop R, Klosterkotter J. Neurocognitive indicators of clinical highrisk states for psychosis: a critical review of the evidence. Neurotox Res. 2010;18(3-4):272-286

46. Seidman LJ, Giuliano AJ, Meyer EC, Addington J, Cadenhead KS, Cannon TD, McGlashan TH, Perkins DO, Tsuang MT, Walker EF, Woods SW, Bearden CE, Christensen BK, Hawkins K, Heaton R, Keefe RS, Heinssen R, Cornblatt BA. Neuropsychology of the prodrome to psychosis in the NAPLS consortium: relationship to family history and conversion to psychosis. Arch Gen Psychiatry. 2010; 67(6): 578-588.

47. Allen P, Seal M, Valli I, Fusar-Poli P, Perlini C, Day F, Wood S, Williams $S$, McGuire P. Altered prefrontal and hippocampal function during verbal encoding and recognition in people with prodromal symptoms of psychosis. Schizophr Bull. 2011;37(4):746-56.

48. Sabb FW, van Erp TG, Hardt ME, Dapretto M, Caplan R, Cannon TD, Bearden CE. Language network dysfunction as a predictor of outcome in youth at clinical high risk for psychosis. Schizophr Research. 2010;116(23):173-183.

49. Stone JM, Howes OD, Egerton A, Kambeitz J, Allen P, Lythgoe DJ, O'Gorman RL, McLean MA, Barker GJ, McGuire P. Altered relationship 
between hippocampal glutamate levels and striatal dopamine function in subjects at ultra high risk of psychosis. Biol Psychiatry. 2010;68(7):599-602.

50. Borgwardt SJ, McGuire PK, Aston J, Gschwandtner U, Pfluger MO, Stieglitz RD, Radue EW, Riecher-Rossler A. Reductions in frontal, temporal and parietal volume associated with the onset of psychosis. Schizophr Res. 2008(2-3);106: 108-114.

51. Mourao-Miranda J, Bokde AL, Born C, Hampel H, Stetter M, 2005. Classifying brain states and determining the discriminating activation patterns: Support Vector Machine on functional MRI data. Neuroimage. 2005;28(4): 980-995.

52. Koutsouleris N, Meisenzahl EM, Davatzikos C, Bottlender R, Frodl T, Scheuerecker J, Schmitt G, Zetzsche T, Decker P, Reiser M, Moller HJ, Gaser C Use of neuroanatomical pattern classification to identify subjects in at-risk mental states of psychosis and predict disease transition. Arch Gen Psychiatry. 2009;66(7):700-712. 